\title{
A COLOCAÇÃO DOS PRONOMES CLÍTICOS NO PORTUGUÊS BRASILEIRO E NO PORTUGUÊS LUANDENSE: UMA CARACTERIZAÇÃO SOCIOLINGUÍSTICA
}

\author{
Manoel Crispiniano Alves da Silva ${ }^{1}$; Silvana Silva de Farias Araújo ${ }^{2}$ \\ 1. Bolsista PIBIC/CNPq, Graduando em Letras Vernáculas, Universidade Estadual de Feira de Santana, e-mail: \\ Silvamanoe1403@yahoo.com.br \\ 2. Orientadora, Departamento de Letras e Artes (DLA), Universidade Estadual de Feira de Santana, e-mail: \\ silvana.uefs.2014@gmail.com
}

PALAVRAS-CHAVE: Clíticos; Português Angolano; Português Brasileiro.

\section{INTRODUÇÃO}

A sócio-história do Português Brasileiro (doravante PB) foi marcada por sucessivos contatos linguísticos. Em princípio, entre os portugueses e os povos indígenas, falantes das inúmeras línguas autóctones. E, posteriormente, de forma mais acentuada com os negros escravizados, oriundos da África, que adquiriram a língua alvo (português) como segunda língua através da oralidade e de oitiva, sem passarem pelo crivo da educação formal. Entretanto, mesmo que tenha havido contexto favorável à formação de uma língua pidgin ou crioula, encontra-se desacreditada a hipótese que o PB é o resultado de um crioulo prototípico. Contudo, houve um processo de transmissão linguística irregular (LUCCHESI, 2001, 2015) deixando marcadas na gramática da variante brasileira, em especial na sua vertente popular. Assim, faz-se necessário realizar estudos contrastivos entre a variedade brasileira e a língua portuguesa falada em outras ex-colônias de Portugal, pois esse cotejo pode trazer elementos para o debate sobre a relevância do contato linguístico na formação sócio-histórica do PB. Desse modo, este trabalho visa a analisar a colocação dos pronomes clíticos no português falado em Luanda, capital de Angola, investigando os contextos sintáticos e os grupos de fatores que favorecem a variante proclítica em lexias verbais simples, ou seja, com um único verbo. Com os resultados aqui obtidos, procurou-se desenvolver um estudo comparativo com pesquisas já realizadas na realidade linguística do Brasil, em que foi investigado o fenômeno em foco nesta pesquisa, analisando, dessa forma, as semelhanças e as diferenças entre ambas as variedades do português.

\section{MATERIAL E MÉTODOS OU METODOLOGIA}

Adota-se o modelo teórico-metodológico da Teoria da Variação e Mudança Linguística, também denominada Sociolinguística Quantitativa ou Variacionista com base nos postulados de Labov (2008[1972]. Esse é o modelo adotado em função de ser teoricamente coerente e metodologicamente eficaz para a descrição de uma comunidade de fala numa perspectiva da variação, já que concebe a língua como uma realidade heterogênea e social.

Os dados da pesquisa foram levantados a partir do corpus do acervo linguístico do projeto "Em busca das raízes do português brasileiro", sediado no Núcleo de estudos da Língua Portuguesa (NELP) da Universidade Estadual de Feira de Santana (UEFS). As entrevistas sociolinguísticas do tipo DID (Diálogo entre Informante e Documentador) foram gravadas entre o ano de 2008 e 2013 no município de Luanda. A amostra encontra-se estratificada da seguinte forma: Sexo (masculino, feminino), Faixa etária (I- 20 a 30 anos/II36 a 50 anos/ III- acima de 52 anos), Escolaridade (baixa ou nula/ superior), Língua Materna (Português/ línguas africanas) e Local de Nascimento (Capital/ Interior).

Controlaram-se as variáveis extralinguísticas acima citadas e as variáveis linguísticas: tipo de oração, clítico, elemento que antecede o verbo e oração coordenada sindética. Para obtenção dos pesos relativos e valores percentuais, utilizou-se o programa computacional Goldvarb X. 


\section{RESULTADOS E/OU DISCUSSÃO}

A base de dados desta pesquisa foi formada por 507 ocorrências. Os resultados alcançados estão expostos na Tabela 01:

Tabela 1: Distribuição da colocação dos clíticos em lexias verbais simples no português falado em Luanda

$\begin{array}{ccc} & \text { Percentuais } & \text { Freq. } \\ \text { Pré-verbal } & 75 \% & 380 / 507 \\ \text { Pós-verbal } & 25 \% & 127 / 507\end{array}$

Os resultados acima descritos mostram que a colocação preferida dos angolanos é a pré-verbal, com o índice de 75\% (380 ocorrências) e25\% (127) da pós-verbal, não havendo registro no corpus de mesóclise, desse modo, confirmando o que afirma Vieira (2003, p.05) ao estudar a variedade brasileira, moçambicana e europeia: "A colocação intraverbal está em flagrante desuso na modalidade oral da Língua Portuguesa".A colocação dos clíticos é um fenômeno sintático que distancia a variedade brasileira da europeia. $\mathrm{Na}$ realidade sociolinguística brasileira predomina a generalização da variante proclítica (LOBO, 1992; FERREIRA; ALKMIM, 2011; CARNEIRO, 2016, dentre outros), enquanto o "Português de Camões" caracteriza-se por ser essencialmente enclítico. Assim, os resultados aqui alcançados apontam para uma aproximação entre a variedade brasileira e a angolana e um distanciamento dessas face à europeia e à moçambicana (VIEIRA, 2003), sendo a próclise a posição que prevalece nessas duas ex-colônias portuguesas.

Para aferirmos a atuação dos grupos de fatores socioculturais sobre o objeto estudado, foram controladas cinco variáveis, a saber, faixa etária, nível de escolaridade, sexo, língua materna e região de origem do informante, entretanto, dessas apenas duas foram selecionadas como favorecedoras da colocação pré-verbal, nível de escolaridade e local de nascimento. Em relação às variáveis de natureza linguística, foram eleitos os seguintes contextos sintáticos: "tipo de oração", "clítico" e "elemento que antecede o verbo".

Nesse sentido, em relação à variável escolaridade, os informantes com baixa ou nula escolaridade preferem a próclise, apresentando um peso relativo de (.69),enquanto para os de nível superior nota-se uma queda da posição pré-verbal, com peso relativo de (.31), perfazendo uma diferença estatisticamente de 38 pontos. Esses resultados confirmam a hipótese aventada inicialmente de que a ênclise seria encontrada com uma maior frequência na fala dos sujeitos falantes da norma culta, pois é a forma canônica adquirida por meio do processo de escolarização.

No tocante ao local de nascimento dos informantes, os indivíduos que nasceram no interior do país são os que mais usam a próclise (peso relativo $\mathbf{. 5 9}$ ) em comparação àqueles que nasceram na capital (.35).

A tradição gramatical prescreve que não se pode iniciar período ou oração com pronome oblíquo átono (ROCHA LIMA, 2001; BECHARA, 2009), contudo, o que é prescrito não faz parte do comportamento linguístico dos brasileiros, como atesta Carneiro (2016, p. 141) "[n]o PB contemporâneo, prevalece a próclise em orações com verbo em posição inicial (V1), um contexto exclusivamente enclítico (V-cl) ao longo da história da língua portuguesa em Portugal". Assim, portanto, pode-se concluir que se trata de uma inovação do PB, pois até os falantes não escolarizados de Portugal preferem categoricamente a ênclise nesse contexto (VIEIRA, 2012). Semelhante ao que ocorre na língua portuguesa brasileira, esse contexto sintático é estatisticamente favorecedor da variante proclítica (.59) na variedade angolana. A seguir, expõem-se alguns exemplos extraídos do corpus examinado para ilustrar o que foi supracitado: 
(1)

INF: "Com a família, ah... é... isso tem acontecido principalmente visitar os irmãos, sobrinhos, os primos, enfim... já... isso acontece. Nos encontramos, às vezes, entre amigos, hoje agora já não tenho, as amizades aqui, todos eles têm outros rumos, né?” [...] (A., Faixa II, $\mathrm{H}, \mathrm{NC})^{1}$

(2)

INF: Me chamo A. V. M. (Faixa III, M, NC).

O gramático Rocha Lima (2011) prescreve que o uso da próclise é obrigatório nas orações subordinadas. As pesquisas têm mostrado que esse contexto, no português do Brasil, seja na modalidade oral (LOBO, 1992), seja na escrita (SHEI, 2003) é essencialmente proclítico. Esse resultado é encontrado no PA, apresentando (.74) de favorecimento da próclise, havendo, dessa forma, uma confluência sociolinguística entre ambas as variedades do português.

Por outro lado, ao observar os pesos relativos das variantes "Sujeito sem fator de próclise (.39) e "Oração coordenada sindética" (.26), verifica-se que esses contextos são desfavorecedores do uso da próclise. Porém, "Depois de pausa" (.48) e em "Oração principal" (.47) consideram-se como contextos neutros.

Ao controlar o elemento que precede o verbo, pode-se afirmar que, quando a lexia verbal vem precedida na estrutura frasal por "Sintagma Nominal (SN) pronome pessoal", obtendo peso relativo de (.60)", "SN- Sujeito Indefinido (.69)", "Sintagma adverbial de negação (.96)" e "Outros sintagmas adverbiais (.52)" há um favorecimento da implementação da próclise.

Os resultados alcançados para a variável "tipo de clítico" mostram que a forma "vos", pode ser considera um arcaísmo na variedade angolana, pois não foi encontrada, no corpus examinado, uma única ocorrência, assim, coadunando com a pesquisa de Lobo (1992, p.172), em que "[...] podendo-se afirmar, de resto, ser essa uma forma totalmente extinta do português brasileiro contemporâneo, em qualquer das suas variantes diatópicas, diafásicas ou diastráticas".

Em relação aos demais clíticos, nota-se que esses exercem interferência na sua própria colocação na estrutura oracional, havendo uma forte tendência à próclise. Os pronomes de primeira pessoa do singular (me com peso relativo de.53 e o te apresentando .73) e do plural (nos, .57) apresentam um padrão de comportamento majoritariamente proclítico, fato esse que não se verifica com os de terceira pessoa, com exceção ao dativo lhe, com peso relativo de .64 .

\section{CONSIDERAÇÕES FINAIS}

Este trabalho visou a investigar a colocação dos pronomes clíticos em estruturas com lexias verbais simples e os resultados alcançados apontam para uma aproximação entre o PB e o PA, sendo a variante proclítica a preferida dos angolanos, perfazendo um total de $75 \%$ de 507 ocorrências. Nesse sentido, o programa Goldvarb X selecionou como favorecedoras da implementação da próclise as variáveis linguísticas "Tipo de Oração", "Clítico" e "Elemento que antecede o verbo". E, em relação às variáveis extralinguísticas formam eleitas "escolaridade" e "local de nascimento".

Sabe-se que, quando o verbo está em posição inicial absoluta, a norma padrão condena a anteposição do clítico. Porém, a literatura tem mostrado que esse contexto é fortemente favorecedor da próclise na língua portuguesa brasileira, o que não se observa nem na norma

\footnotetext{
${ }^{1}$ Legenda: Faixa Etária: Faixa I (20 a 30 anos), Faixa II (36 a 50 anos), Faixa III (acima de 52 anos), Sexo: M (Masculino), F (Feminino), NC (Falante da Norma Culta), NP ( Falante da Norma Popular).
} 
vernacular de Portugal em que a ênclise é categórica (VIEIRA, 2012). Esse contexto, na variedade luandense, assim como no $\mathrm{PB}$, favorece a próclise.

Portanto, essas semelhanças sintáticas podem ser compreendidas como uma forma dos angolanos estarem firmando a sua identidade linguística, pois como defende Teixeira (2013), o português falado nessa comunidade de fala está em processo de constituição.

\section{REFERÊNCIAS}

BECHARA, Evanildo. Moderna gramática da língua portuguesa. 37. Ed. ver.,ampl. e atual. Rio de Janeiro: Nova Fronteira, 2009.

CARNEIRO, Zenaide de Oliveira Novais. Colocação de clíticos em orações finitas em duas vertentes do português oral feirense: um contexto não variável. In: ALMEIDA, Norma Lucia Fernandes de; ARAUJO, Silvana Silva de Farias; TEIXEIRA, Eliana Sandra Pitombo; CARNEIRO, Zenaide de Oliveira Novais. (Org.). Variação Linguística em Feira de Santana. Feira de Santana: UEFS Editora, 2016, v. 1, p. 141-174.

FEREIRA, Wisla M. A C; ALKMIM, Mônica G. R. de. A colocação do pronome clítico na fala do dialeto mineiro. I CONGRESSO NACIONAL DE ESTUDOS LINGUÍSTICOS, VITÓRIA-ES, 18 A 21 DE OUTUBRO DE 2011.

LABOV, W. Padrões sociolinguísticos. São Paulo: Parábola, 2008 [1972].

LUCCHESI, Dante. As duas grandes vertentes da história sociolingüística do Brasil (15002000). DELTA. São Paulo. v.17, n.1, p. 97-132, 2001.

LUCCHESI, Dante. Língua e Sociedade partidas: a polarização sociolinguística do Brasil. São Paulo: Contexto, 2015.

LOBO, Tânia. A colocação dos pronomes clíticos em português: duas sincronias em confronto. Dissertação de Mestrado. Faculdade de Letras da Universidade de Lisboa, Lisboa, 1992.

ROCHA LIMA, Carlos Henrique da.Gramática normativa da língua portuguesa. 49. ed. Rio de Janeiro: José Olympio, 2011.

SCHEI, Ane. A colocação pronominal do português brasileiro: a língua literária brasileira.2. ed. São Paulo: Humanistas/ FFLCH/ USP, 2003.

TEIXEIRA, Eliana S. Pitombo. Aspetos da pronominalização do português vernacular de Luanda: uma comparação com o português do Brasil.In: Norma da Silva Lopes; Lígia Pelonda Silva Bulhões; Cristina dos Santos Carvalho.(Org). Sociolinguística: estudo da variação, da mudança e da sócio-história do português brasileiro. Feira de Santana: EDUEFS, 2013, p.145-167.

VIEIRA, Silvia. Rodrigues. Colocação pronominal nas variedades européia, brasileira e moçambicana do português: para a definição da natureza do clítico em Português. In: BRANDÃO, S.F.; MOTA, M.A.C da. (Org.). Análise contrastiva de variedades do Português. 1ed.Rio de Janeiro: In-Fólio, v. 1, p. 37-60, 2003.

VIEIRA, Maria. de Fatima. O português europeu e a colocação dos pronomes átonos. Diacrítica, Porto, v.26, n.1, p.299-330, 2012. 